\title{
Relationship between Perceived Neighborhood Characteristics and Vigorous Physical Activity among Adult Seoul Residents
}

\author{
Chung Gun Lee ${ }^{1)}$, Youngtae $\mathrm{Cho}^{1,2)}$
}

School of Public Health, Seoul National University ${ }^{11}$, Population Research Center, University of Texas-Austin²)

Objectives : Vigorous physical activity is a well-known method to promote people's health. This research aims to investigate whether perceived neighborhood characteristics affect vigorous physical activity among adult Seoul residents (aged 19 to 64).

Methods : Utilizing the 2005 Seoul Citizens Health Indicators Survey data, this study estimates the probability of vigorous physical activity. Particular attention is given to the effects of three perceived neighborhood characteristics (satisfaction with relationship to the neighborhood, satisfaction with park and recreational facilities, and satisfaction with public security). Logistic regression models are analyzed separately by gender for the parameter estimation.

Results : Vigorous physical activity is positively associated with three perceived neighborhood characteristics for women, while neither significant nor substantive association is found for men.

Conclusions : As vigorous physical activity among Seoul citizens is differentially affected by perceived neighborhood characteristics and by gender, a different approach will be needed to increase vigorous physical activity of men and women in Seoul.

J Prev Med Public Health 2009;42(4):215-222

Key words : Perceived neighborhood characteristics, Vigorous physical activity, Gender, Seoul, Adult

\section{INTRODUCTION}

Regular physical activity is a well-known method to prevent chronic diseases [1]. It also has positive effects on mental health by improving self-esteem and reducing stress [1]. Physical activity can be divided into vigorous physical activity and moderate physical activity. The American College of Sports Medicine (ACSM) defines vigorous physical activity as activity that makes people sweat or breathe hard for at least 20 minutes 3 or more days a week, and moderate physical activity as activity that makes people breathe somewhat harder than normal for 30 minutes 5 or more days a week [2]. Additionally, these guidelines state that people should follow this criterion continuously to maintain and promote their health [2]. According to many studies, vigorous physical activity can help prevent chronic diseases such as coronary artery disease, hypertension, hyperlipemia, diabetes, and obesity more efficiently than can moderate physical activity [3]. Vigorous physical activity also has a more powerful effect on prolonging the lifespan than does moderate physical activity [4]. Additionally, performing vigorous physical activity is a more efficient way to achieve the ACSM recommendation because time constraint is a frequently reported reason for physical inactivity [5]. In line with these advantages, vigorous physical activity has been included in the list of goals for the Establishment of a New Health Plan 2010 project in Korea [6]. Despite the clear advantages of vigorous physical activity, only $14.4 \%$ of Koreans engaged in vigorous physical activity in 2005 [6]. This is very low compared to United States of America, where $23 \%$ of people performed vigorous physical activity in 2002 [6].

Research on physical activity behaviors used to consider the micro level determinants (individual characteristics), but this was not enough to explain people's physical activity behaviors [7]. Based on a socioecological model, recent research has begun to consider the macro level determinants (environmental characteristics) in addition to micro level determinants. According to this model, social, physical, and political environments interact in people's lives and ultimately affect people's behavior independent of individual characteristics. A consideration of socioecological factors helps to explain physical behavior more accurately and therefore provide the tools necessary to understand how to change people's behavior more efficiently.

Many studies have investigated the effects of environment on health and physical activity behavior. These studies measured environments using objective or subjective methods $[8,9]$. Some aspects of the environment can be measured by objective data, such as the number of physical activity facilities and 
population density. On the other hand, a subjectively measured environment considers how individuals perceive their environment. Because objectively and subjectively measured environments have different characteristics, it may be ideal to consider both together $[8,10]$. Not many reports consider both of these characteristics of environments due to the limited data available. The current research considered only subjectively measured environments for the same reason. Because Seoul has very large population and high social density, an objectively measured environment in one area may affect people in other areas [11].

The perceived (i.e., subjectively measured) environments considered in this research include satisfaction with public security, satisfaction with the neighborhood, and satisfaction with park and recreation facilities. According to many studies, people are more active when they think that someone supports their exercise $[12,13]$, the level of general social support is high [14], they participate in various kinds of social activities [15], or they can trust their neighbors [16]. These factors are related to social capital [15], and to satisfaction with the neighborhood, which can be understood as social capital in this research [9].

Few reports are available showing that perceived public security affects people's physical activity [17-19]. This may be because people perform physical activity only in safe places such as indoor facilities [20]. However, this assumption has yet to be proven. Because perceived public security is an important factor in studies on physical activity, more research about this factor will be needed.

Many reports show that physical activity facilities and parks affect people's physical activity. People are more active when they think that exercise facilities and parks are close to their home $[16,17,21,22]$, the status of exercise facility is well maintained [12], and they have many opportunities to use exercise facilities and parks $[13,23]$. Only one report showed that perceived physical activity facilities do not affect people's physical activity [14].

Taken together, these data indicate that various kinds of perceived environments affect people's physical activity. Because all the studies above are cross-sectional, the possibility remains that physical activity affects people's perceived environments rather than vice versa. That is, people who are physically active may have a more positive outlook in general, which is then reflected in their responses to the survey. The perception of one's environment is likely to be affected by objectively measured environmental conditions, and if people have negative thoughts about their environments, this negative perception may be attributed to negative characteristics of actual environments [10]. In many cases, people in a low socioeconomic area perceive their environments negatively, and this can be understood in the same way. In other words, the actual environment affects people's perception of their environment; ultimately, people will not go outside and therefore will be physically inactive if they think that their environment is not safe due to negative characteristics such as crime [8-10].

Although interest in the effect of environments on physical activity is growing in international studies, insufficient research exists on this topic in Korea. Many reports on physical activity in Korea have either focused on individual characteristics rather than on the environments $[24,25]$, have had very small sample sizes [26], or did not distinguish between vigorous and moderate physical activity [27]. Because the determinants of vigorous and moderate physical activity are different, physical activity-related studies should distinguish intensity and type of physical activity [28,29]. Utilizing the 2005 Seoul Citizens Health Indicators Survey data, this research investigated the effects not only of various kinds of perceived environments, but also of socioeconomic characteristics on vigorous physical activity of Seoul citizens aged 19 to 64 .

\section{MATERIALS AND METHODS}

\section{Data}

This study used data gathered in the 2005 Seoul Citizens Health Indicators Survey. Seoul city officials gathered this data to learn about Seoul citizens' health status, to produce a health index for people's health promotion, and to produce statistical data on community health to facilitate the establishment of a community healthcare plan. Further information from this report is mentioned broadly through official reports and in other research [30,31]. Follow-ups from survey participants were excluded from the data. Because of their inability to perform vigorous physical activity, people who answered Need help' or 'Can't do it' to Activities of Daily Living questions were excluded. People aged over 65 were also excluded because the performance of vigorous physical activity can be strongly affected by very old age. After excluding these people and people with missing data on major variables (i.e., perceived neighborhood characteristic and vigorous physical activity), the total sample size was 14,767 .

\section{Variables and Measurement}

The dependent variable in this study was vigorous physical activity. As mentioned above, the ACSM defines vigorous physical activity as activity that makes people sweat or breathe hard for at least 20 minutes 3 or more days a week. Additionally, ACSM suggests that people should follow this criterion continuously to maintain or promote good health [2]. Because it is more meaningful to consider physical activity in terms of the maintenance and promotion of people's health than to just consider physical activity with no particular goal in mind, this research referred to 
ACSM's guidelines and defined vigorous physical activity as activity that makes people sweat or breathe hard for at least 30 minutes 3 or more days a week. On the Seoul Citizens Health Indicators Survey, the question, How long do you sustain vigorous physical activity per day?' provided only these answers: less than 15 minutes, $15-29$ minutes, 30-59 minutes, and 1 hour or more; hence, we were unable to identify people who exercised 20 minutes. However, our analysis may be more conservative using 30 minutes rather than the 20 minutes suggested by ACSM. Vigorous physical activity in this research is selfreported, and the validity and reliability of selfreported physical activity have been identified as acceptable [32,33].

The most important independent variable in this research is the individual's perception of his/her environment. The environment-related questions in the 2005 Seoul Citizens Health Indicators Survey addressed people's satisfaction with their relationship to the neighborhood, public security, and park and recreation facilities. We defined these variables as perceived neighborhood characteristics because they reflect people's satisfaction with their neighborhood.

Satisfaction with the neighborhood and public security were measured using a 12-point Likert scale on which 0 indicated very dissatisfied and 11 indicated very satisfied with the neighborhood and public security. Satisfaction with park and recreation facilities was measured using a 5-point Likert scale on which 1 meant very dissatisfied and 5 meant very satisfied with the park and recreation facilities. These three variables were considered as continuous variables.

The general characteristics of participants that were considered as control variables in this research are age, marital status, job, standardized income, education. Age was divided as 19-29, 30-39, 40-49, 50-64; and marital status was classified as single, married, and other (separated, divorced, and widowed).
Education was classified as middle school or lower, high school, and college or higher. If data regarding education were missing, the individual was included in the category of middle school or lower. Jobs were classified as blue collar, white collar, housewife, student, and other. Because no males were classified as housewives, housewife was excluded from the analysis for male participants. Standardized income was calculated by dividing household income by the number of persons in the family, and the results were categorized as 500,000 won or less, 510,000-1,000,000 won, 1,010,000-1,500,000 won, 1,510,000-2,000,000 won, $2,010,000-3,000,000$ won, $3,010,000$ won or more, and missing.

Health related variables such as perceived health status, smoking, and stress were also considered as control variables because the relationships between these variables and physical activity have been reported in many studies, and many physical activity-related studies have also considered these variables as control variables [34,35]. Perceived health status was measured using a 5-point scale on which 1 indicated very good health status and 5 meant very poor health status compared to other people in the same age group. Stress was classified as very high stress, some stress, not very stressed, and no stress. Smoking was classified as current smokers and current nonsmokers.

\section{Analysis}

Chi-square analysis was used to assess differences between vigorously active and inactive people classified according to general characteristics. Analysis of variance (ANOVA) was used to compare the mean satisfaction with the environment according to presence or absence of vigorous physical activity. To investigate relationships between vigorous physical activity and perceived neighborhood characteristics, we used logistic regression analysis controlling for general characteristics of participants and health related variables.
Because the type and intensity of activity that causes people to sweat or breathe hard may be different according to gender, we performed our analyses separately by gender. As shown in Table 1, employment of participants was very different according to gender. About 55\% of women were housewives, whereas no men were housewives. Perceived neighborhood characteristics may be very different for men who spend more time outside of their neighborhood due to their employment than for women, because housewives are likely to spend more time within their neighborhoods. Therefore, it was very reasonable to analyze the data separately for women and for men. Statistical analyses were performed using SAS ver. 9.1 (SAS Institute, Inc., Cary, NC, USA).

\section{RESULTS}

\section{Descriptive Analysis}

The rates of vigorous physical activity according to general characteristics of participants are presented in Table 1. The number of women $(56.5 \%)$ in the sample was higher than that of men (56.5\%). Among men, participants were evenly distributed according to age, $69.1 \%$ of men were married, and $55.4 \%$ of men had attained a college education or higher. Also, $43.1 \%$ and $39.1 \%$ of men were white- and blue-collar workers, respectively, and men in these two categories accounted for the majority of male participants. The standardized incomes of almost $52 \%$ of the men were in the $510,000-1,000,000$ won category. Just over $1 \%$ of men received $3,010,000$ won or more, and this group constituted the smallest income group among the male participants. A majority (61.6\%) of men perceived their health as poor compared to other people in their age group, and less than $1 \%$ of men perceived their health as very good compared to others in the same age group. The percentage of men who smoked (53.9\%) was slightly higher than that of nonsmokers (46.1\%), and most of the men reported being a somewhat or very stressed. Distributions of 
Table 1. Percentage distributions of sample characteristics by gender and vigorous physical activity (PA) among adult Seoul residents in 2005

\begin{tabular}{|c|c|c|c|c|c|c|}
\hline \multirow{2}{*}{ Variables } & \multicolumn{3}{|c|}{ Men } & \multicolumn{3}{|c|}{ Women } \\
\hline & no. & Vigorous PA (\%) & $\mathrm{p}\left(\mathrm{x}^{2}\right)$ & no. & Vigorous PA (\%) & $\mathrm{p}\left(\mathrm{x}^{2}\right)$ \\
\hline \multicolumn{7}{|l|}{ Age } \\
\hline $19-29$ & 1,367 & 10.17 & 0.0077 & 1,601 & 7.56 & $<0.0001$ \\
\hline $30-39$ & 1,831 & 8.30 & & 2,645 & 9.38 & \\
\hline $40-49$ & 1,919 & 11.05 & & 2,414 & 12.72 & \\
\hline $50-64$ & 1,308 & 11.70 & & 1,682 & 11.00 & \\
\hline \multicolumn{7}{|l|}{ Marital status } \\
\hline Single & 1,711 & 9.41 & 0.0165 & 1,564 & 8.12 & 0.0005 \\
\hline Married & 4,437 & 10.82 & & 5,900 & 11.20 & \\
\hline \multicolumn{7}{|l|}{ Separated } \\
\hline Divorced & 224 & 4.91 & & 492 & 9.15 & \\
\hline \multicolumn{7}{|l|}{ Widowed } \\
\hline Missing & 53 & 7.55 & & 386 & 7.25 & \\
\hline \multicolumn{7}{|l|}{ Education } \\
\hline$\leq$ Middle school & 437 & 8.92 & $<0.0001$ & 1,006 & 10.74 & 0.6921 \\
\hline High school & 2,430 & 8.27 & & 3,971 & 10.50 & \\
\hline$\geq$ College & 3,558 & 11.69 & & 3,365 & 9.99 & \\
\hline \multicolumn{7}{|l|}{ Job } \\
\hline Blue collar & 2,512 & 9.67 & 0.0530 & 1,504 & 9.64 & $<0.0001$ \\
\hline White collar & 2,771 & 11.19 & & 1,360 & 9.04 & \\
\hline Housewife & 0 & 0.00 & & 4,573 & 11.63 & \\
\hline Student & 625 & 10.24 & & 444 & 7.43 & \\
\hline Others & 517 & 7.54 & & 461 & 6.07 & \\
\hline \multicolumn{7}{|l|}{ Standardized income (Won) } \\
\hline$\leq 500,000$ & 1,096 & 7.21 & $<0.0001$ & 1,516 & 7.45 & 0.0002 \\
\hline $510,000-1,000,000$ & 3,333 & 9.81 & & 4,307 & 11.05 & \\
\hline $1,010,000-1,500,000$ & 939 & 11.82 & & 1,200 & 12.33 & \\
\hline $1,510,000-2,000,000$ & 539 & 16.51 & & 719 & 9.60 & \\
\hline $2,010,000-3,000,000$ & 171 & 10.53 & & 185 & 12.97 & \\
\hline$\geq 3,010,000$ & 72 & 12.50 & & 79 & 6.33 & \\
\hline Missing & 275 & 8.36 & & 336 & 7.74 & \\
\hline \multicolumn{7}{|l|}{ Health } \\
\hline Very healthy & 54 & 12.96 & $<0.0001$ & 78 & 7.69 & 0.0803 \\
\hline Healthy & 535 & 7.29 & & 927 & 7.87 & \\
\hline Normal & 1,282 & 8.19 & & 1,910 & 10.21 & \\
\hline Unhealthy & 3,957 & 10.41 & & 4,950 & 10.75 & \\
\hline Very unhealthy & 597 & 15.58 & & 477 & 11.53 & \\
\hline \multicolumn{7}{|l|}{ Smoke } \\
\hline Smoking & 3,462 & 8.87 & 0.0001 & 536 & 8.58 & 0.1713 \\
\hline Non-smoking & 2,963 & 11.78 & & 7,806 & 10.44 & \\
\hline \multicolumn{7}{|l|}{ Stress } \\
\hline Very high stress & 1,022 & 8.02 & 0.0133 & 927 & 7.44 & 0.0058 \\
\hline Some stress & 4,370 & 10.23 & & 5,712 & 10.45 & \\
\hline Not very stressed & 909 & 12.54 & & 1,529 & 11.12 & \\
\hline No stress & 124 & 10.48 & & 174 & 14.37 & \\
\hline Total & 6,425 & 10.21 & & 8,342 & 10.32 & \\
\hline
\end{tabular}

Table 2. Mean neighborhood satisfaction score by vigorous physical activity among adult Seoul residents in 2005

\begin{tabular}{|c|c|c|c|c|c|c|}
\hline \multirow[b]{2}{*}{ Variables } & \multicolumn{3}{|c|}{ Men } & \multicolumn{3}{|c|}{ Women } \\
\hline & Participants & $\begin{array}{c}\text { Non- } \\
\text { participants }\end{array}$ & $\mathrm{p}(\mathrm{t}$-test $)$ & Participants & $\begin{array}{c}\text { Non- } \\
\text { participants }\end{array}$ & $\mathrm{p}$ (t-test) \\
\hline Public security & 6.20 & 6.08 & 0.07 & 6.37 & 6.01 & $<0.0001$ \\
\hline Relationship to the neighborhood & 6.31 & 6.18 & 0.06 & 6.63 & 6.28 & $<0.0001$ \\
\hline Park and recreation facilities & 3.06 & 2.98 & 0.08 & 3.17 & 2.98 & $<0.0001$ \\
\hline
\end{tabular}

women in these areas were very different. A majority of women (47.6\%) had attained a high school education. A total of $54.8 \%$ of women were housewives, and most women (93.6\%) answered that they were nonsmokers.

The rates of vigorous physical activity for men and women were reported to be $10.2 \%$ and $10.3 \%$, respectively. Although this is an unexpected result, a number of studies show similar vigorous physical activity rates in men and women $[24,36]$. In the present study, these similar rates may be attributable to a large proportion of women who are housewives and who may have sufficient time to perform vigorous physical activity. No large differences in vigorous physical activity rates were found between men and women. It is interesting that young people (aged 19 to 39) were less likely to be vigorously active than were older people (aged 40 or more). Separated, divorced, or widowed men were less likely to be vigorously active than were married and single men, but this tendency did not appear in women. Women who were housewives were more likely to be vigorously active than were other women. It is interesting that men and women who perceived their health as poor compared to others the same age were more likely to be vigorously active. People who think their health is poor may have a positive attitude toward vigorous physical activity because they need to improve their health. However, this finding may be misleading because other variables may have confounded the result. Current nonsmokers were more likely to be vigorously active than current smokers among both men and women. Also, stress was negatively related to the rate of participation in vigorous physical activity in both men and women.

Table 2 shows the mean satisfaction with the environment according to vigorous physical activity. We used ANOVA to compare mean satisfaction with each environment according to vigorous physical activity, and the results showed that people who were vigorously active had higher mean satisfaction than did those who were inactive. However, these differences were statistically significant only for women.

\section{Multivariate Analysis}

Table 3 presents the results of the logistic regression analysis concerning the possible correlates of vigorous physical activity. These two models were analyzed separately for men and women. Model 1 is the result of a logistic regression analysis that considered only control variables. Model 2 considered perceived neighborhood characteristics in addition to the 
variables considered in model 1 . In model 1 , relationships between control variables and vigorous physical activity were very similar to results from Table 1. However, the statistical significance of these relationships differed by gender. Socioeconomic characteristics such as level of standardized income and education were significant determinants of vigorous physical activity only in men. In women, young age and a high level of stress were the only factors that significantly affected vigorous physical activity. Perceived health status was a significant determinant of vigorous physical activity in men and women, and smoking significantly affected vigorous physical activity in men only.

Adding perceived neighborhood characteristics in model 1 did not change the relationships between control variables and vigorous physical activity to a measurable degree. However, the significant effect of a high level of stress on women's vigorous physical activity disappeared in model 2 . This suggests that perceived neighborhood characteristics affect vigorous physical activity independently of the control variables considered here, with the exception of stress. Interestingly, perceived neighborhood characteristics did not significantly affect vigorous physical activity in men, whereas all three perceived neighborhood characteristics significantly affected vigorous physical activity in women. That is to say, women who are satisfied with public security, park and recreation facilities, and their relationship with their neighborhoods are more likely to engage in vigorous physical activity.

\section{DISCUSSION}

In this study, perceived neighborhood characteristics significantly affected vigorous physical activity for women only. This result supports other research showing that women's physical activity behavior is more likely to be influenced by social factors [36], perceived

Table 3. Logistic regression models of vigorous physical activity among adult Seoul residents in 2005

\begin{tabular}{|c|c|c|c|c|}
\hline \multirow[b]{2}{*}{ Dependent variables } & \multicolumn{2}{|c|}{ Model 1} & \multicolumn{2}{|c|}{ Model 2} \\
\hline & $\begin{array}{c}\text { Men } \\
\text { OR }(95 \% \mathrm{CI})\end{array}$ & $\begin{array}{c}\text { Women } \\
\text { OR }(95 \% \mathrm{Cl})\end{array}$ & $\begin{array}{c}\text { Men } \\
\text { OR }(95 \% \mathrm{CI})\end{array}$ & $\begin{array}{c}\text { Women } \\
\text { OR }(95 \% \mathrm{CI})\end{array}$ \\
\hline \multicolumn{5}{|l|}{ Age } \\
\hline $19-29$ & $0.74(0.50-1.11)$ & $0.58^{+}(0.41-0.83)$ & $0.75(0.50-1.11)$ & $0.60^{+}(0.42-0.86)$ \\
\hline $30-39$ & $0.58^{+}(0.44-0.76)$ & $0.74 *(0.58-0.94)$ & $0.58^{+}(0.44-0.77)$ & $0.75^{*}(0.59-0.96)$ \\
\hline $40-49$ & $0.86(0.67-1.09)$ & $1.09(0.87-1.36)$ & $0.86(0.67-1.09)$ & $1.09(0.87-1.36)$ \\
\hline \multicolumn{5}{|l|}{$50-64$ (ref) } \\
\hline \multicolumn{5}{|l|}{ Marital status } \\
\hline \multicolumn{5}{|l|}{ Single (ref) } \\
\hline Married & $1.19(0.87-1.64)$ & $0.82(0.59-1.14)$ & $1.19(0.87-1.64)$ & $0.81(0.58-1.13)$ \\
\hline \multicolumn{5}{|l|}{ Separated } \\
\hline Divorced & $0.52(0.26-1.04)$ & $0.74(0.48-1.15)$ & $0.53(0.27-1.05)$ & $0.75(0.48-1.16)$ \\
\hline \multicolumn{5}{|l|}{ Widowed } \\
\hline Missing & $0.73(0.25-2.18)$ & $0.53^{*}(0.32-0.89)$ & $0.73(0.25-2.18)$ & $0.51^{+}(0.30-0.85)$ \\
\hline \multicolumn{5}{|l|}{ Education } \\
\hline$\leq$ Middle school & $0.76(0.51-1.12)$ & $1.07(0.80-1.43)$ & $0.75(0.51-1.12)$ & $1.07(0.80-1.42)$ \\
\hline $\begin{array}{l}\text { High school } \\
\geq \text { College (ref) }\end{array}$ & $0.69^{+}(0.56-0.85)$ & $0.95(0.80-1.12)$ & $0.69^{+}(0.56-0.85)$ & $0.95(0.80-1.13)$ \\
\hline \multicolumn{5}{|l|}{ Job } \\
\hline \multicolumn{5}{|l|}{ Blue collar (ref) } \\
\hline White collar & $1.00(0.82-1.22)$ & $0.99(0.75-1.30)$ & $1.00(0.82-1.21)$ & $0.98(0.74-1.30)$ \\
\hline Housewife & N/A & $1.24(1.00-1.53)$ & N/A & $1.21(0.98-1.51)$ \\
\hline Student & $0.93(0.62-1.40)$ & $0.93(0.58-1.50)$ & $0.93(0.62-1.40)$ & $0.91(0.57-1.48)$ \\
\hline Others & $0.83(0.57-1.20)$ & $0.74(0.48-1.15)$ & $0.83(0.57-1.21)$ & $0.76(0.49-1.18)$ \\
\hline \multicolumn{5}{|l|}{ Standardized income (Won) } \\
\hline$\leq 500,000$ & $0.47^{+}(0.33-0.66)$ & $0.76(0.55-1.06)$ & $0.47^{+}(0.33-0.66)$ & $0.82(0.59-1.13)$ \\
\hline $510,000-1,000,000$ & $0.57^{+}(0.44-0.74)$ & $1.11(0.84-1.45)$ & $0.57^{+}(0.44-0.74)$ & $1.13(0.86-1.48)$ \\
\hline $1,010,000-1,500,000$ & $0.69^{*}(0.51-0.94)$ & $1.28(0.94-1.74)$ & $0.69^{*}(0.51-0.94)$ & $1.28(0.95-1.74)$ \\
\hline \multicolumn{5}{|l|}{$1,510,000-2,000,000$ (ref) } \\
\hline \multirow{2}{*}{$\begin{aligned} 2,010,000 & -3,000,000 \\
& \geq 3,010,000\end{aligned}$} & $0.63(0.36-1.08)$ & $1.37(0.83-2.26)$ & $0.63(0.37-1.09)$ & $1.38(0.83-2.29)$ \\
\hline & $0.89(0.42-1.89)$ & $0.65(0.25-1.67)$ & $0.90(0.42-1.90)$ & $0.66(0.25-1.69)$ \\
\hline Missing & $0.48^{+}(0.29-0.78)$ & $0.83(0.52-1.34)$ & $0.49^{+}(0.30-0.80)$ & $0.90(0.56-1.46)$ \\
\hline \multicolumn{5}{|l|}{ Stress } \\
\hline Very high stress & $0.83(0.44-1.55)$ & $0.55^{*}(0.33-0.90)$ & $0.86(0.46-1.61)$ & $0.61(0.37-1.01)$ \\
\hline Some stress & $1.02(0.56-1.84)$ & $0.71(0.46-1.11)$ & $1.05(0.58-1.90)$ & $0.76(0.49-1.17)$ \\
\hline Not very stressed & $1.17(0.63-2.16)$ & $0.74(0.47-1.17)$ & $1.20(0.65-2.22)$ & $0.77(0.49-1.22)$ \\
\hline \multicolumn{5}{|l|}{ No stress (ref) } \\
\hline \multicolumn{5}{|l|}{ Smoke } \\
\hline Smoking & $0.80^{+}(0.68-0.94)$ & $0.93(0.68-1.28)$ & $0.79^{+}(0.67-0.94)$ & $0.95(0.69-1.31)$ \\
\hline \multicolumn{5}{|l|}{ Non-smoking (ref) } \\
\hline Health & $1.25^{+}(1.11-1.40)$ & $1.14^{*}(1.03-1.25)$ & $1.24^{+}(1.11-1.40)$ & $1.11^{*}(1.01-1.23)$ \\
\hline Public security & & & $0.99(0.94-1.05)$ & $1.09+(1.03-1.14)$ \\
\hline Relationship to the neighborhood & & & $1.05(0.97-1.13)$ & $1.13^{+}(1.05-1.21)$ \\
\hline Park and recreation facilities & & & $1.03(0.98-1.09)$ & $1.08^{+}(1.03-1.14)$ \\
\hline$-2 \mathrm{LL}$ & $4,120.29$ & $5,444.35$ & $4,117.58$ & $5,393.85$ \\
\hline
\end{tabular}

${ }^{*} \mathrm{p}<0.05,{ }^{+} \mathrm{p}<0.01, \mathrm{CI}$ : confidence interval

security $[17,22]$, and the availability of lowcost or free facilities [22] than is that of men. In short, women are more likely to be influenced by psychological factors than are men [37]. Perceived neighborhood characteristics only affected women's vigorous physical activity in this research, and this may be because women consider the characteristics of their neighborhoods more than men do. However, more research with more specific data will be needed to clarify this explanation.

These results suggest that when women are satisfied with public security in their neighborhoods, they are more likely to engage in vigorous physical activity. This result supports other research on the relationship between perceived safety and physical activity [17-19]. However, the majority of studies show that perceived safety does not affect people's physical activity [20-22]. This may be because these studies did not specify the intensity of physical activity, although reports on physical activity should consider the type and intensity of physical activity [28,29]. The vigorous physical activity considered in this research is very different from moderate physical activity. Unlike moderate physical activity such as walking and cleaning house, vigorous physical activity is more likely to be performed outside the house. As a matter of 
fact, only $3 \%$ of the vigorously active people in this study answered that they perform vigorous physical activity inside the home. The rest answered that they perform vigorous physical activity outside the house at a gym, fitness club, playground, park, mountain, walking trails, or bicycle trails. Because vigorous physical activity needs more space than moderate physical activity does, it is likely to be performed in places where population density is relatively low. Therefore, women's vigorous physical activity is affected by their satisfaction with public security because such activity is likely to be performed outside the house in areas of low population density. More data will be needed to support this explanation, including information on what time of day vigorous physical activity is performed. Based on the results of this study, factors that increase women's satisfaction with public security included variables such as closed-circuit TV (CCTV), street lamps, and police stations, and measures to improve such services should be adopted to encourage women to exercise.

Satisfaction with park and recreation facilities was also found to affect women's vigorous physical activity. This result is also consistent with other reports. Many studies have shown that people are more active when they believe exercise facilities and parks are close to their homes [16,17,21,22], the exercise facilities are well maintained [12], or they have many opportunities to use exercise facilities and parks $[13,23]$. We confirmed that women in the city of Seoul are also affected by satisfaction with park and recreation facilities in their neighborhoods. To increase vigorous physical activity among women, the city of Seoul needs to implement plans to increase women's satisfaction with park and recreation facilities.

Women's satisfaction with their neighborhoods has been found to affect their vigorous physical activity. Satisfaction with neighborhoods can be understood as social capital [9], and the result of this research is consistent with other studies that considered various kinds of social capital. According to many reports, people are more active when they think there is a person who supports their exercising [12,13], the level of general social support is high [14], they are participating in various kinds of social activities [15], and they can trust their neighbors [16]. Satisfaction with neighborhoods can be interpreted as similar to participation in social activities. If the level of social participation is high, many possibilities may appear for getting support for exercise [16]. However, it is also possible that the people who participate in many kinds of social activities are more likely to perform vigorous physical activity because they are more active people. For a more precise explanation, mediators between satisfaction with neighborhoods and vigorous physical activity should be found.

Stress is also an important factor in this research, because the significant effect of a high level of stress on women's vigorous physical activity was apparent in model 2 . This may be due to the effect on women's vigorous physical activity of the environment-related variables added in model 2. Women's stress may be an antecedent variable that affects vigorous physical activity through perceived neighborhood characteristics. Furthermore, because stress has been considered an important variable in studies on physical activity [34,35], further studies about stress and physical activity will be needed.

This research had three major limitations. First, because this is a cross-sectional study, the possibility must be considered that physical activity affected people's perceived environments. In other words, the causal relationship between perceived neighborhood characteristics and vigorous physical activity is unclear because people who are physically active may have brought a generally positive frame of mind to the survey. Second, this study did not consider objectively measured environment. The reason for not using an objective environment in this study is because Seoul has a very high population and social density, and an objectively measured environment in one area could affect people in other areas [11]. Because perceived environments can be affected by the individual's expectations and desires [38], many limitations may arise in measuring physical environments. To investigate the effects of environments on physical activity more accurately, objectively and subjectively measured environments should be considered together [10,33]. Third, because participants in this study included Seoul citizens, it only provides information about overall vigorous physical activity in the city of Seoul. To understand vigorous physical activity behavior of Seoul citizens more accurately, similar studies should be performed with more specific groups. Despite these limitations, this study is meaningful for two reasons. First, this study is the first large-scale physical activity related study to investigate a large population $(14,767$ Seoul citizens) in Korea. Second, we focused specifically on vigorous physical activity in the analysis, whereas most research on physical activity has not.

According to results of this study, vigorous physical activity among Seoul citizens is differentially affected by perceived neighborhood characteristics and by gender. The more satisfied women are with public security, parks and recreation facilities, and the security of their neighborhoods, the more likely they are to perform vigorous physical activity. Vigorous physical activity among men was not affected by these three perceived neighborhood characteristics. To increase vigorous physical activity among Seoul citizens (aged 19 to 64), a different approach will be needed for men than for women. To increase women's vigorous physical activity, it will be important to increase women's satisfaction with the characteristics of their neighborhoods. Perceived environments are likely to be affected by objectively measured environments, and if people have negative thoughts about their environments, there is a possibility 
that this negative thinking may be attributed to negative characteristics of the actual environments [10]. In other words, to increase satisfaction with the perceived characteristics of neighborhoods, the actual environment should be improved. Satisfaction with public security can be increased by installing more CCTV and street lamps and by increasing the number of police officials to provide more active patrols. Satisfaction with one's relationship with the neighborhood can be increased by focusing on social capital. Organizing exercise clubs and holding sports competitions may be good techniques for building social capital. Satisfaction with park and recreation facilities can be increased by increasing the number of facilities and improving the quality of existing facilities. Because men's vigorous physical activity was not affected by satisfaction with perceived neighborhood characteristics, more studies about environmental factors that affect vigorous physical activity of men should be performed.

\section{REFERENCES}

1.US Department of Health and Human Services, Centers for Disease Control and Prevention, National Center for Chronic Disease Prevention and Health Promotion. Physical Activity and Health: A Report of the Surgeon General. Atlanta, GA: US Department of Health and Human Services; 1996.

2. Haskell WL, Lee IM, Pate RR, Powell KE, Blair SN, Franklin BA, et al. Physical activity and public health: Updated recommendation for adults from the American College of Sports Medicine and the American Heart Association. Med Sci Sports Exerc 2007; 39(8): 1423-1434.

3. Swain DP, Franklin BA. Comparison of cardioprotective benefits of vigorous versus moderate intensity aerobic exercise. Am J Cardiol 2006; 97(1): 141-147.

4.Lee IM, Paffenbarger RS Jr. Associations of light, moderate, and vigorous intensity physical activity with longevity. Am J Epidemiol 2000; 151(3): 293-299.

5. Bertrais S, Preziosi P, Mennen L, Galan P, Hercberg S, Oppert JM. Sociodemographic and geographic correlates of meeting current recommendations for physical activity in middle-aged French adults: The Supplmentation en Vitamines et Mineraux Antioxydants (SUVIMAX) Study. Am J Public Health 2004; 94(9): 1560-1566.

6. Ministry of Health and Welfare, Korea institute for health and social affairs. Establish of New Health Plan 2010. Policy Rep 2005; 74(2): 162. (Korean)

7. Sallis JF, Bauman A, Pratt M. Environmental and policy interventions to promote physical activity. Am J Prev Med 1998; 15(4): 379-397.

8. Humpel N, Owen N, Leslie E. Environmental factors associated with adults' participation in physical activity: A review. Am J Prev Med 2002; 22(3): 188-199.

9. Cho Y, Park GS, Echevarria-Cruz S. Perceived neighborhood characteristics and health of adult Koreans. Soc Sci Med 2005; 60(6): 1285-1297.

10. Ross CE, Mirowsky J. Neighborhood disadvantage, disorder, and health. $J$ Health Soc Behav 2001; 42(3): 258-276.

11. Jung SW, Cho Y. Neighborhood characteristics and individual health under Korean context. J Prev Med Public Health 2005; 38(3): 259-266. (Korean)

12.Duncan M, Mummery K. Psychosocial and environmental factors associated with physical activity among city dwellers in regional queensland. Prev Med 2005; 40(4): 363-372.

13. Bamana A, Tessier S, Vuillemin A. Association of perceived environment with meeting public health recommendations for physical activity in seven European countries. J Public Health 2008; 30(3): 274-281.

14. Sanderson BK, Foushee HR, Bittner V, Cornell CE, Stalker V, Shelton S, et al. Personal, social, and physical environmental correlates of physical activity in rural AfricanAmerican women in Alabama. Am J Prev Med 2003; 25 (3 Suppl 1): 30-37.

15.Lindstrom M, Hanson BS, Ostergren PO. Socioeconomic differences in leisure-time physical activity: The role of social participation and social capital in saping health related behavior. Soc Sci Med 2001; 52(3): 441-451.

16. Addy CL, Wilson DK, Kirtland KA, Ainsworth BE, Sharpe P, Kimsey D. Associations of perceived social and physical environmental support with physical activity and walking behavior. Am J Public Health 2004; 94(3): 440-443.

17. Foster C, Hillsdon M, Thorogood M. Environmental perceptions and walking in english adults. J Epidemiol Community Health 2004; 58(11): 924-928.

18. Centers for Disease Control and Prevention. Neighborhood safety and the prevalence of physical inactivity: Selected states, 1996.
MMWR Morb Mortal Wkly Rep 1999; 48(7): 143-146.

19. Gordon-Larsen P, McMurray RG, Popkin BM. Determinants of adolescent physical activity and inactivity patterns. Pediatrics 2000; 105(6): 83-90.

20. Bedimo-Rung AL, Mowen AJ, Cohen DA. The significance of parks to physical activity and public health: A conceptual model. Am J Prev Med 2005; 28(2 Suppl 2): 159-168.

21. Hoehner CM, Brennan Ramirez LK, Elliott MB, Handy SL, Brownson RC. Perceived and objective environmental measures and physical activity among urban adults. Am J Prev Med 2005; 28(2 Supple 2): 105-116.

22. Garcia Bengoechea E, Spence JC, McGannon KR. Gender differences in perceived environmental correlates of physical activity. Int J Behav Nutr Phys Act 2005; 2: 12.

23.Rutten A, Abel T, Kannas L, von Lengerke T, Luschen G, Diaz JA, et al. Self reported physical activity, public health, and perceived environment: Results from a comparative European study. J Epidemiol Community Health 2001; 55(2): 139-146.

24. Lee JH, Lee MS, Na BJ, Bae SH, Hwang HJ, Kim KY, et al. A study on the physical activity status and its determinant factors in some rural people. J Korea Sport Res 2007; 18(2): 433450. (Korean)

25. Cho EH. A study on the resocialization and continuity of involvement in physical activity among elderly.J Korean Phys Edu Assoc Girls Women 2003; 17(1): 99-114. (Korean)

26. Cho JH, Song KJ. Rasch calibration and evaluation of perceived barriers to exercise and walking among college women. Korean J Meas Eval Phys Edu Sport Sci 2003; 5(1): 2946. (Korean)

27. Kim MS, Kim YM. The influence of sports environment factors on the dropouts from the life sports program. Korean J Phys Educ 2003; 42(3): 111-121.(Korean)

28. Deeter TE. Does Attitudinal commitment predict physical activity participation? J Sport Behav 1988; 11(4): 177-192.

29. King AC, Stokols D, Talen E, Brassington GS, Killingsworth R. Theoretical approaches to the promotion of physical activity: Forging a transdisciplinary paradigm. Am J Prev Med 2002; 23(2 Suppl 1): 15-25.

30. Jung Y, Cho Y, Oh J. Differential effect of family income on self-rated health by age: Analysis of Seoul citizens health indicators survey 2001, 2005. J Prev Med Public Health 2007; 40(5): 381-387 (Korean).

31. Chun EJ, Jang SN, Cho SI, Cho Y, Moon OR. Disparities in participation in health 
examination by socio-economic position among adult Seoul residents. J Prev Med Public Health 2007; 40(5): 345-350 (Korean).

32.LaPorte RE, Montoye HJ, Caspersen CJ. Assessment of physical activity in epidemiologic research: Problems and prospects. Public Health Rep 1985; 100(2): 131-146.

33. Washburn RA, Montoye HJ. The assessment of physical activity by questionnaire. Am J Epidemiol 1986; 123(4): 563-576.
34. Dishman RK, Sallis JF, Orenstein DR. The determinants of physical activity and exercise. Public Health Rep 1985; 100(2): 158-171.

35. Sherwood NE, Jeffery RW. The behavioral determinants of exercise: Implications for physical activity interventions. Anпи Rev Nutr 2000; 20(1): 21-44.

36. Sallis JF, Hovell MF, Hofstetter CR. Predictors of adoption and maintenance of vigorous physical activity in men and women. Prev Med 1992; 21(2): 237-251.
37. Verbrugge LM. The twain meet: Empirical explanations of sex differences in health and mortality. J Health Soc Behav 1989; 30(3): 282-304.

38. Kirtland KA, Porter DE, Addy CL, Neet MJ, Williams JE, Sharpe PA, et al. Environmental measures of physical activity supports: Perception versus reality. Am J Prev Med 2003; 24(4): 323-331. 